\title{
Improvement of Pulse Pattern for Space Vector Modulated Matrix Converters
}

\author{
Kichiro Yamamoto Member (Kagoshima University) \\ Katsuji Shinohara Member (Kagoshima University) \\ Tatsuya Mori Student Member (Kagoshima University)
}

Keywords: matrix converter, space vector modulation, pulse pattern

Novel modulation which consists of conventional space vector modulation (SVM) and carrier signal modulation for matrix converters is proposed.

Conventional indirect SVM for matrix converters decides duties of $d_{\gamma}$ and $d_{\delta}$ for rectifying stage and duties of $d_{\alpha}, d_{\beta}$ and $d_{0}$ for inverting stage. And then, the duties are combined to generate new duties for the entire matrix converter by products of the corresponding duties. Moreover, the switching pattern for the entire matrix converter is decided by the phases of input voltage vector and output voltage command vector and the duties for the matrix converter.

Proposed novel SVM calculates duties $d_{\min X}, d_{\operatorname{mid} X}$ and $d_{\max X}$, where $d_{\min X}$ is a duty for the switch between the input phase whose phase voltage is minimum value and the output phase $X, d_{\text {mid } X}$ a duty for the switch between the input phase whose phase voltage is medium and $X$ and $d_{\max X}$ a duty for the switch between the input phase whose phase voltage is maximum and $X$. The subscript $X$ is $u$ or $v$ or $w$, where $u, v$ and $w$ stand for the output phases.

The duties $d_{\min X}, d_{\operatorname{mid} X}$ and $d_{\max X}$ are compared to the triangle carrier (Fig. 1) and the switching pattern for the matrix converter is decided. The pattern generated by proposed SVM has the following features;

- Zero output voltage vector is realized by connecting all of output phases to the input phase voltage with medium value.

- Only one of the output phases is switched for an output voltage pattern change.

- The switching numbers within a sampling period are eight.

- There is no switching between the input phase voltage with minimum value and the voltage with maximum value.

- Zero output voltage is not used when the output phase voltage command is higher value and the maximum input line to line voltage is not used when the voltage command is lower value.

Conventional and proposed SVM were compared by the simulation program PSIM and conditions and parameters for the simulation are listed in Table 1. Figures 2 and 3 show simulated waveforms of output line to line voltage. From the figures, it is clear that proposed SVM does not use zero output voltage when the output phase voltage command is higher value and does not use the maximum input line to line voltage (dashed line) when the voltage command

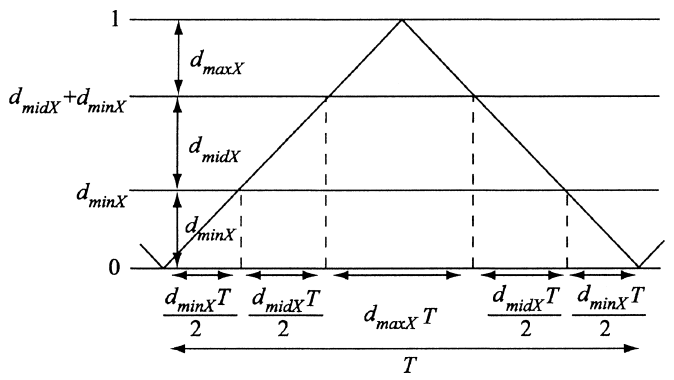

Fig. 1. Method of PWM pattern generation is lower value. Figures 4 and 5 demonstrate frequency spectra for each waveform in Figs. 2 and 3. Proposed SVM can reduce the harmonic components except around carrier frequency.

Table 1. Specification for simulation

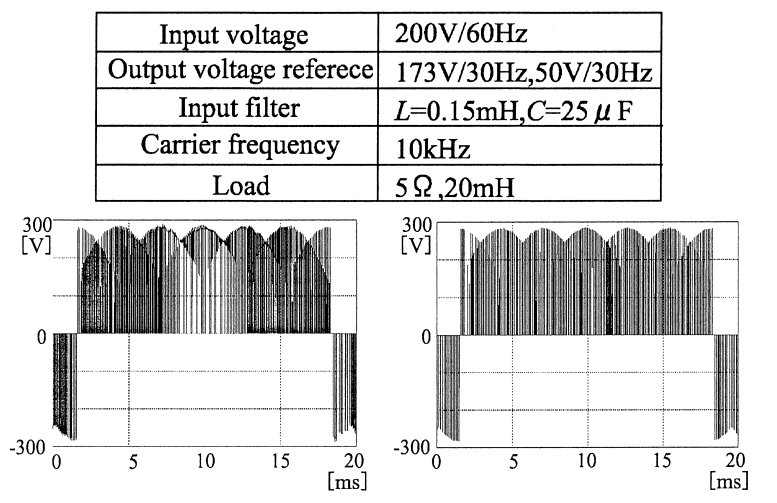

(a) Output voltage reference $173 \mathrm{~V}$

(b) Output voltage reverence $50 \mathrm{~V}$

Fig. 2. Output line to line voltage waveforms (conventional SVM)

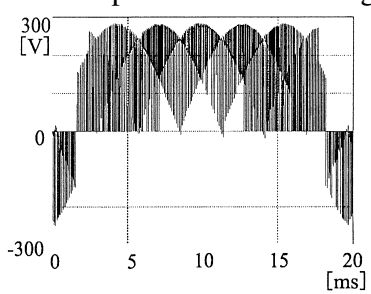

(a) Output voltage reference $173 \mathrm{~V}$

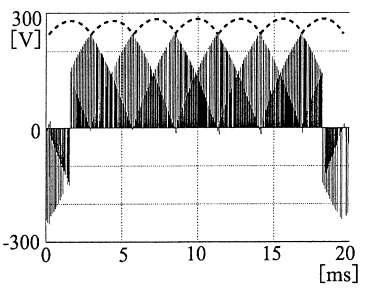

(b) Output voltage reverence $50 \mathrm{~V}$
Fig. 3. Output line to line voltage waveforms (proposed SVM)

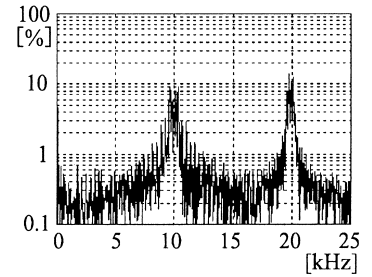

(a) Output voltage reference $173 \mathrm{~V}$

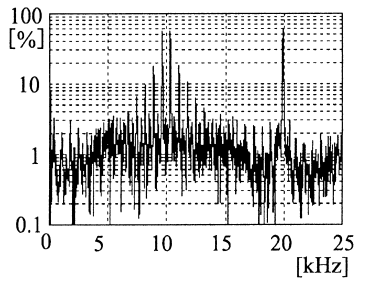

(b) Output voltage reverence $50 \mathrm{~V}$
Fig. 4. Frequency spectra of output line to line voltage (conventional SVM)

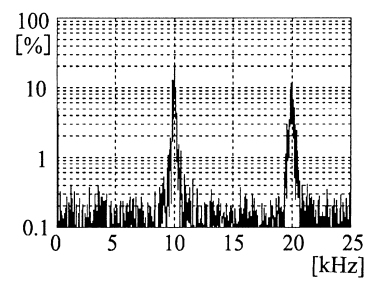

(a) Output voltage reference $173 \mathrm{~V}$

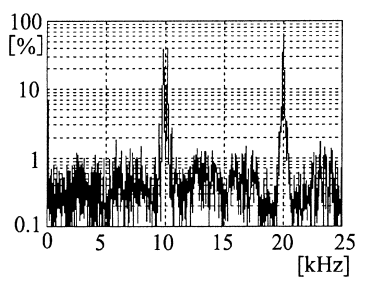

(b) Output voltage reverence $50 \mathrm{~V}$
Fig. 5. Frequency spectra of output line to line voltage (proposed SVM) 


\title{
マトリックスコンバータの空間ベクトル変調における パルスパターンの改善
}

\author{
正 員 山本 吉朗* 正員篠原 勝次* \\ 学生員 森 辰也*
}

\section{Improvement of Pulse Pattern for Space Vector Modulated Matrix Converters}

Kichiro Yamamoto*, Member, Katsuji Shinohara*, Member, Tatsuya Mori*, Student Member

\begin{abstract}
Novel modulation which consists of conventional space vector modulation (SVM) based on a virtual AC/DC/AC conversion and carrier signal modulation for matrix converters is proposed. In this proposed modulation, duties for the switching pattern decided by conventional SVM are changed into those for each switch of matrix converter. The new duties for each output phase are compared with the triangle carrier. By using proposed modulation, switchings between the input phase voltage with minimum value and the voltage with maximum value are eliminated.

In this paper, the conventional SVM and proposed modulation are explained. Next, for both conventional and proposed modulations waveforms of input current, output voltage and output current and their frequency spectra are calculated by PSIM simulation program. Simulation results show the proposed modulation can reduce harmonics of output voltage waveforms.
\end{abstract}

キーワード：マトリックスコンバータ，空間ベクトル変調，パルスパターン

Keywords: matrix converter, space vector modulation, pulse pattern

\section{1. まえがき}

マトリックスコンバータは, 商用交流電圧を振幅可変, 周 波数可変の交流電圧に直接変換する回路であり，従来の整 流回路一インバータシステムに比べて, EMI, 効率, 変換器 の体積等の点において優れていることから盛んに研究が行 われている。マトリックスコンバータの変調法として, 出 力電圧指令と入力電流指令に基づきマトリックスコンバー 夕の 9 つのスイッチの PWM パターンを直接発生させる直 接 $\mathrm{AC} / \mathrm{AC}$ 変調方式 ${ }^{(1)}$ ，およびマトリックスコンバータを仮 想的に電流形 PWM 整流回路と電圧形 PWM インバータの 組み合わせとして制御し，最終的にマトリックスコンバー タのスイッチに合わせて合成する仮想 $\mathrm{AC} / \mathrm{DC} / \mathrm{AC}$ 変調方 式(2)がある。後者における問題点として，仮想インバータ において零電圧ベクトルとなるスイッチングパターンを形 成した場合，仮想整流器において，そのスイッチング状態 に関わらず全入力相の電流が流れなくなり，入力電流波形 に歪みが発生することがあげられる。文献 (2)では, 仮想イ ンバータ側のキャリアを変形することでこの問題を解決し

\footnotetext{
*鹿児島大学工学部電気電子工学科

干 890-0065 鹿児島市郡元 1-21-40

Dep. of E. and E. Eng., Kagoshima University

1-21-40, Korimoto, Kagoshima 890-0065
}

ている。またこの問題を解決するのに, 仮想整流回路とイ ンバータの制御に空間ベクトル変調を用いる方法が提案さ れている ${ }^{(3) \sim(5)}$ 。さらに仮想 $\mathrm{AC} / \mathrm{DC} / \mathrm{AC}$ 変調方式に関して, 変調率が低い場合において入力最大の線間電圧を用いずに PWM 変調を行うことで, 出力電圧の高調波を低減させる 方式も提案されている(6)。

本論文では，仮想 $\mathrm{AC} / \mathrm{DC} / \mathrm{AC}$ 変調方式における仮想整 流器および仮想インバータを空間べクトル変調 $(\mathrm{SVM})$ に よって制御する方式 (3) (5) に関して, キャリア周期における 出力相電圧のパルスパターンを改善する方式を提案する。 提案の変調法は, マトリックスコンバータの空間ベクトル 変調によって求められた出力パターンのデューティをマト リックスコンバータ各スイッチのデューティへと変換し, それを出力相ごとにキャリア比較 (7)することによって最終 的なスイッチングパターンを決定するものである。

以下では，まず従来の空間べクトル変調の概要を述べた 後, 提案の変調法について説明する。次に, シミュレーショ ンにより, 従来の空間ベクトル変調と提案の空間ベクトル 変調の出力電圧波形を比較し, 提案の空間べクトル変調が 従来法に比べて高調波を抑制できることを示す ${ }^{(8)}$ 。

\section{2. 従来の空間ベクトル変調 ${ }^{(3)(4)}$}

〈2·1〉 マトリックスコンバータの空間ベクトル 本 


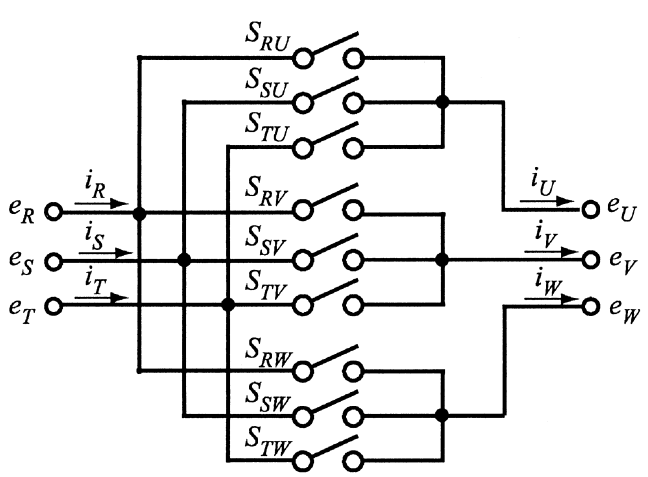

Fig. 1. Matrix converter

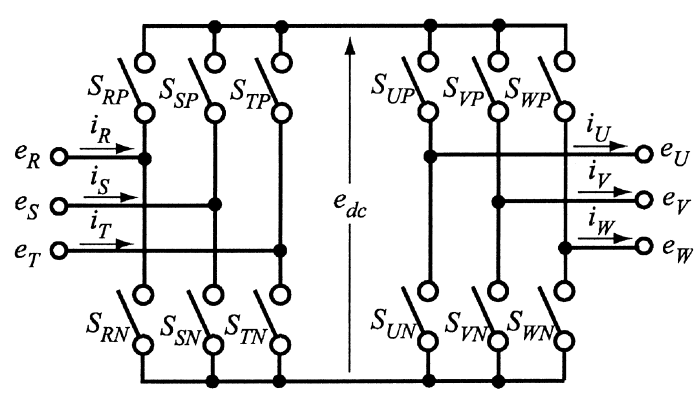

Fig. 2. AC/DC/AC converter

章では，文献 (3) (4) を参考にして，従来の空間べクトル変 調について説明する。

Fig. 1 にマトリックスコンバータを示す。これを Fig. 2 に 示す仮想整流器ーインバータに置き換えて考える。仮想整流 器は入力電流を入力側から見て力率 1 の正弦波電流に制御 する。一方，仮想インバータは出力電圧の振幅と位相を制 御する。マトリックスコンバータの入力側の電圧, 電流, 出 力側の電圧, 電流の空間ベクトル表現は以下のようになる。

$$
\begin{aligned}
& \underline{E}_{i n}=\frac{2}{3}\left(e_{R}+e_{S} e^{j(2 \pi / 3)}+e_{T} e^{j(4 \pi / 3)}\right) \cdots \\
& \underline{I}_{\text {in }}=\frac{2}{3}\left(i_{R}+i_{S} e^{j(2 \pi / 3)}+i_{T} e^{j(4 \pi / 3)}\right) \cdots \\
& \underline{E}_{\text {out }}=\frac{2}{3}\left(e_{U}+e_{V} e^{j(2 \pi / 3)}+e_{W} e^{j(4 \pi / 3)}\right) \\
& \underline{I}_{\text {out }}=\frac{2}{3}\left(i_{U}+i_{V} e^{j(2 \pi / 3)}+i_{W} e^{j(4 \pi / 3)}\right) \cdots
\end{aligned}
$$

ここで, $\underline{E}_{i n}$ は入力相電圧に対する空間べクトル表現, $\underline{I}_{i n}$ は 入力電流に対する空間べクトル表現， $\underline{E}_{\text {out }}$ は出力相電圧に 対する空間ベクトル表現， $\underline{I}_{\text {out }}$ は出力電流に対する空間べ クトル表現である。

Fig. 3 に入力電流指令ベクトルとその分配について示す。 仮想整流器側の空間ベクトルでは, 入力側の力率を 1 にする ため入力電流指令ベクトル $\underline{I}_{i n}^{*}$ を入力電圧ベクトル $\underline{E}_{i n}$ と同 相となるように制御する $\underline{I}_{i n}^{*}$ が存在するセク夕において $\underline{I}_{i n}^{*}$ よりも遅れた位置にある成分を $d_{\gamma} I_{\gamma}$, 進んだ位置にある成 分を $d_{\delta} I_{\delta}$ としている。このデューティは次式で表される。

$$
d_{\gamma}=m_{c} \sin \left(\frac{\pi}{3}-\theta_{i n}^{*}\right)
$$

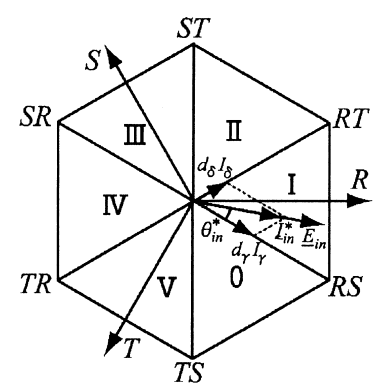

Fig. 3. Input current reference vector

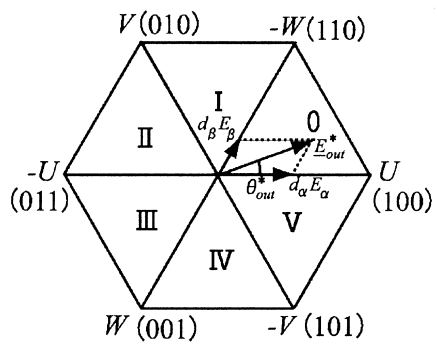

Fig. 4. Output voltage reference vector

Table 1. Combination of rectifier side duties and inverter side duties

\begin{tabular}{|c|c|c|c|c|c|}
\hline rectifier & \multicolumn{2}{|c|}{$d_{\gamma}$} & \multicolumn{2}{|c|}{$d_{\delta}$} & $d_{0}$ \\
\hline inverter & $d_{\alpha}$ & \multicolumn{2}{|c|}{$d_{\beta}$} & $d_{\alpha}$ & $d_{0}$ \\
\hline combination & $d_{\gamma \alpha}$ & $d_{\gamma \beta}$ & $d_{\delta \beta}$ & $d_{\delta \alpha}$ & $d_{0}$ \\
\hline
\end{tabular}

$d_{\delta}=m_{c} \sin \left(\theta_{i n}^{*}\right)$

ここで，仮想直流リンク電圧を $e_{d c}$ とすれば $m_{c}\left(=2 e_{d c} /\right.$ $\left.\left(3\left|\underline{E}_{i n}\right|\right)\right)$ と書ける。仮想インバータにおいては, Fig. 4 の出 力電圧指令べクトル $\underline{E}_{\text {out }}^{*}$ を制御する。この場合も $\underline{E}_{\text {out }}^{*}$ が 存在するセクタにおいて $\underline{E}_{\text {out }}^{*}$ より遅れた位置にある成分を $d_{\alpha} E_{\alpha}$, 進んだ位置にある成分を $d_{\beta} E_{\beta}$ としている。出力電 圧振幅の制御は次式の $m_{I}\left(=\sqrt{3}\left|\underline{E}_{\text {out }}^{*}\right| / e_{d c}\right)$ を制御すること によって行われる。

$$
\begin{aligned}
& d_{\alpha}=m_{I} \sin \left(\frac{\pi}{3}-\theta_{\text {out }}^{*}\right) \\
& d_{\beta}=m_{I} \sin \left(\theta_{\text {out }}^{*}\right) \cdots \cdots
\end{aligned}
$$

Table 1 に示すように, 仮想整流器および仮想インバー夕 で求められた (5)〜 (8) 式のデューティを合成することでマ トリックスコンバータの各区間のデューティが得られる。 これらを以下に示す。

$$
\begin{aligned}
& d_{\gamma \alpha}=d_{\gamma} d_{\alpha}=\frac{2 \cdot\left|\underline{E_{\text {out }}^{*}}\right|}{\sqrt{3} \cdot\left|\underline{E_{\text {in }}}\right|} \cdot \sin \left(\frac{\pi}{3}-\theta_{\text {in }}^{*}\right) \cdot \sin \left(\frac{\pi}{3}-\theta_{\text {out }}^{*}\right) \\
& \ldots \ldots \ldots \ldots \ldots \ldots \ldots(9) \\
& d_{\gamma \beta}=d_{\gamma} d_{\beta}=\frac{2 \cdot \mid \frac{E_{\text {out }}^{*} \mid}{\sqrt{3} \cdot\left|\underline{E_{\text {in }}}\right|} \cdot \sin \left(\frac{\pi}{3}-\theta_{\text {in }}^{*}\right) \cdot \sin \left(\theta_{\text {out }}^{*}\right)}{\ldots}
\end{aligned}
$$


Table 2. Switching of the conventional space vector modulation ${ }^{(3)}$

\begin{tabular}{|c|c|c|c|c|c|c|c|c|c|c|c|c|c|c|c|c|c|c|c|c|}
\hline$\underline{R e c}$ & \multicolumn{4}{|c|}{ Sector 0} & \multicolumn{3}{|c|}{ Sector I } & \multicolumn{4}{|c|}{ Sector II } & \multicolumn{4}{|c|}{ Sector III } & \multicolumn{2}{|r|}{ Sector IV } & \multicolumn{3}{|c|}{ Sector V } \\
\hline$\downarrow \operatorname{In} v$ & $d_{r \alpha}$ & $d_{r_{\beta}}$ & $d_{\delta \alpha}$ & $d_{\delta \beta}$ & $d_{\gamma \alpha}$ & $d_{\gamma_{\beta}}$ & \begin{tabular}{|l|l|}
$d_{\delta \alpha}$ & $d_{\delta \beta}$ \\
\end{tabular} & $d_{\gamma \alpha}$ & $d_{\gamma_{\beta}}$ & $d_{\delta \alpha}$ & $d_{\delta \beta}$ & $d_{\gamma \alpha}$ & $d_{\gamma_{\beta}}$ & $d_{\delta \alpha}$ & $d_{\delta \beta}$ & $d_{\gamma \alpha}$ & $\left|d_{\gamma_{\beta}}\right| d_{\delta \alpha} \mid d_{\delta \beta}$ & $d_{r \alpha}$ & \begin{tabular}{l|l|}
$d_{\gamma_{\beta}}$ & $d_{\delta \alpha \alpha}$ \\
\end{tabular} & $d_{\delta \beta}$ \\
\hline 0 & $T S S$ & $T T S$ & $R S S$ & $R R S$ & $R S S$ & $R R S$ & $R T T R R T$ & $R T T$ & $R R T$ & $S T T$ & SST & $S T T$ & $S S T$ & $S R R$ & $S S R$ & $S R R$ & \begin{tabular}{l|l|l|} 
SSR & $T R R$ & $T T R$ \\
\end{tabular} & $T R R$ & \begin{tabular}{|l|l|}
$T T R$ & $T S S$ \\
\end{tabular} & $T T S$ \\
\hline I & $T T S$ & $S T S$ & $R R S$ & $S R S$ & $R R S$ & $S R S$ & $R R T T R T$ & $R R T$ & $T R T$ & $S S T$ & $T S T$ & $S S T$ & TST & SSR $\mid$ & $R S R$ & $S R$ & \begin{tabular}{l|l|l|}
$R S R$ & $T T R$ & $R T R$ \\
\end{tabular} & TTR & RTR TTS & $S T S$ \\
\hline II & STS & STT & $S R S$ & $S R R$ & $S R S$ & $S R R$ & \begin{tabular}{ll|l|}
$T R T$ & $T R R$ \\
\end{tabular} & TRT & $T R R$ & TST & $T S S$ & $T S T$ & TSS & $R S R$ & $R S S$ & $R S R$ & \begin{tabular}{|l|l|l|l|}
$R S S$ & $R T R$ & $R T T$ \\
\end{tabular} & $R T R$ & RTT STS & $S T T$ \\
\hline III & STT & $S S T$ & SRR & $S S R$ & $S R R$ & $S S R$ & \begin{tabular}{|l|l|l|}
$T R R$ & $T T R$ \\
\end{tabular} & TRR & TTR & TSS & $T T S$ & TSS & $T T S$ & $R S S$ & $R R S$ & $R S S$ & $R R S R T T R R T$ & $R T T$ & $|R R T| S T T \mid$ & $S S T$ \\
\hline IV & $S S T$ & $T S T$ & $S S R$ & $R S R$ & $S S R$ & $R S R$ & \begin{tabular}{|l|l|}
$T T R$ & $R T R$ \\
\end{tabular} & TTR & $R T R$ & $T T S$ & STS & $T T S$ & STS & $R R S$ & $S R S$ & $R R S$ & \begin{tabular}{|l|l|l|}
$S R S$ & $R R T$ & $T R T$ \\
\end{tabular} & $R R T$ & \begin{tabular}{|l|l|}
$T R T S S T$ \\
\end{tabular} & $T S T$ \\
\hline $\mathrm{V}$ & TST & $T S S$ & $R S R$ & $R S S$ & $R S R$ & $R S S$ & \begin{tabular}{|l|l|}
$R T R$ & $R T T$ \\
\end{tabular} & RTR & $R T T$ & STS & STT & STS & $S T T$ & SRS & SRR & $S R S$ & \begin{tabular}{l|l|l|}
$S R R$ & $T R T$ & $T R R$ \\
\end{tabular} & TRT & TRRTST & $T S S$ \\
\hline
\end{tabular}

$$
\begin{aligned}
& d_{\delta \alpha}=d_{\delta} d_{\alpha}=\frac{2 \cdot\left|\underline{E_{\text {out }}^{*}}\right|}{\sqrt{3} \cdot\left|\underline{E_{\text {in }}}\right|} \cdot \sin \left(\theta_{\text {in }}^{*}\right) \cdot \sin \left(\frac{\pi}{3}-\theta_{\text {out }}^{*}\right) \\
& d_{\delta \beta}=d_{\delta} d_{\beta}=\frac{2 \cdot\left|\underline{E_{\text {out }}^{*}}\right|}{\sqrt{3} \cdot\left|\underline{E_{\text {in }}}\right|} \cdot \sin \left(\theta_{\text {in }}^{*}\right) \cdot \sin \left(\theta_{\text {out }}^{*}\right) \cdots \\
& d_{0}=1-d_{\gamma \alpha}-d_{\gamma \beta}-d_{\delta \alpha}-d_{\delta \beta}
\end{aligned}
$$

入力電流指令ベクトルおよび出力電圧指令ベクトルが存 在するセク夕に対応したデューティと出力側に接続される 入力電圧 (出力パターン) は Table $2^{(3)}$ となる。この 3 つ並 ぶアルファベットのうち, 左側にあるものは出力 $U$ 相に接 続される入力相を, 中央にあるものは出力 $V$ 相に接続され る入力相を, 右側にあるものは出力 $W$ 相に接続される入力 相を表す。例えば， RSS は出力 $U, V, W$ 相がそれぞれ入 力の $R, S, S$ 相に接続されることを表している。

入力電流指令ベクトルおよび出力電圧指令ベクトルのセ クタに対応するパターンは Table 2 のように決定されるが, 実際にはこれらのパターンをキャリア周期間に配置する必 要がある。ここで，スイッチングに関して，以下のような 2 つの規則がある。

規則 1 :コモンモード電圧を減少させるため, 零電圧べクト ルは入力中間相で実現する。

規則 2 : スイッチング損失削減のため, 1 回のパターン変化 に対して出力 3 相のうちの 1 相のみ接続する入力 相を切り替える。

これらの規則から，スイッチング順序は入力電流指令ベク トルのセクタ番号（Fig. 3 参照）と出力電圧指令べクトル のセク夕番号 (Fig. 4 参照) の和が奇数か偶数かによって, また $\theta_{i n}^{*}$ が $\pi / 6$ より大きいか小さいかによって異なる以下， これについて説明する。

$\langle\mathbf{2} \cdot \mathbf{2}\rangle$ 入力電流指令ベクトルが奇数セクタ（Fig. 5(a) にある場合のスイッチングパターン 入力最大相電圧は 正，入力中間相電圧および入力最小相電圧は負となる。こ のため，零べクトル発生に用いる入力中間相は仮想直流リ ンク電圧の負側に接続されることになる。このとき出力側 の零べクトルは $(000)$ となる。したがって，規則 2 から零 ベクトルの前後のベクトルは Fig. 6 において 0 を 2 つかつ 1 を 1 つ含むべクトルでなければならない。これらのベク トルは，出力電圧指令ベクトルが奇数セクタにある場合だ とデューティが $d_{\beta}$ のベクトル (Fig. 6(a)), 偶数セクタにあ

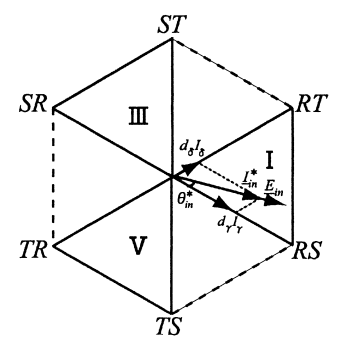

(a) Odd input hexagon sectors

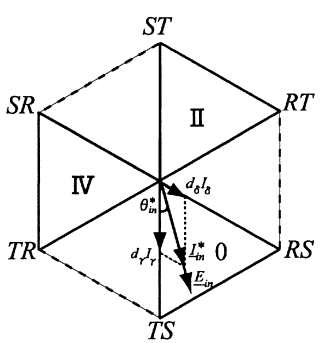

(b) Even input hexagon sectors
Fig. 5. Input current reference vectors

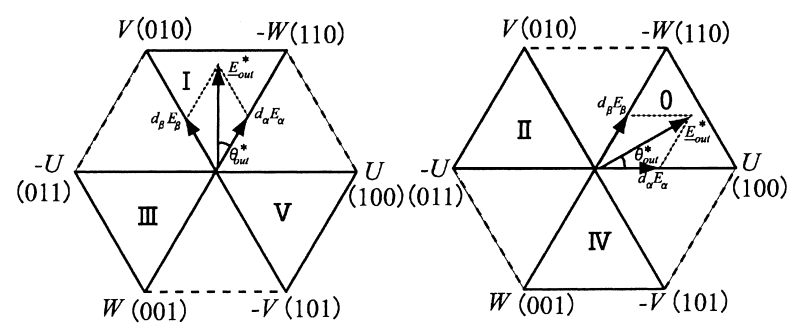

$\begin{array}{ll}\text { (a) Odd input hexagon sectors } & \text { (b) Even input hexagon sectors }\end{array}$

Fig. 6. Output voltage reference vectors

る場合だとデューティ $d_{\alpha}$ のベクトル（Fig. 6(b)）となる。 今, 入力電流指令ベクトルが奇数セクタ I (Fig. 5(a)) で出 力電圧指令ベクトルが奇数セクタ I (Fig. 6(a)) にある場合, $e_{R}>0>e_{T}>e_{S}\left(\theta_{i n}^{*}<\pi / 6\right)$ であるので, 出力ベクトル は (010)を $(T R T)$ または $(S R S) て ゙ ，(110) を(R R T)$ または $(R R S)$ で実現することになる。出力の零べクトルは中間相 電圧で実現するので $(000)$ を $(T T T)$ で実現する。1 回のパ ターン変化で出力 1 相のみの入力相を切り替えるのでキャ リア周期におけるスイッチング順序は以下のようになる。

$$
\underset{(T T T)}{d_{0}} \rightarrow \underset{(T R T)}{d_{\delta \beta}} \rightarrow \underset{(R R T)}{d_{\delta \alpha}} \rightarrow \underset{(R R S)}{d_{\gamma \alpha}} \rightarrow \underset{(S R S)}{d_{\gamma \beta}} \quad\left(\theta_{i n}^{*}<\frac{\pi}{6}\right)
$$

これが $e_{R}>0>e_{S}>e_{T}\left(\theta_{i n}^{*}>\pi / 6\right)$ の場合だと, 入力中 間相が $S$ になるので出力電圧の零べクトル $(000)$ を $(S S S)$ で実現する。この場合のスイッチング順序は以下のように なる。

$$
\underset{(T R T)}{d_{\delta \beta}} \rightarrow \underset{(R R T)}{d_{\delta \alpha}} \rightarrow \underset{(R R S)}{d_{\gamma \alpha}} \rightarrow \underset{(S R S)}{d_{\gamma \beta}} \rightarrow \underset{(S S S)}{d_{0}} \quad\left(\theta_{i n}^{*}>\frac{\pi}{6}\right)
$$

同様に, 入力電流指令ベクトルが奇数セクタ I (Fig. 5(a)) 
で出力電圧指令ベクトルが偶数セクタ $0($ Fig. 6(b) ) にある 場合, 入力側は $e_{R}>0>e_{T}>e_{S}\left(\theta_{i n}^{*}<\pi / 6\right)$ であるので, 1 回のパターン変化で出力 1 相のみの入力相を切り替える とキャリア周期に抒けるスイッチング順序は以下のように なる。

$$
\underset{(T T T)}{d_{0}} \rightarrow \underset{(R T T)}{d_{\delta \alpha}} \rightarrow \underset{(R R T)}{d_{\delta \beta}} \rightarrow \underset{(R R S)}{d_{\gamma \beta}} \rightarrow \underset{(R S S)}{d_{\gamma \alpha}} \quad\left(\theta_{i n}^{*}<\frac{\pi}{6}\right)
$$

これが $e_{R}>0>e_{S}>e_{T}\left(\theta_{i n}^{*}>\pi / 6\right)$ の場合だと, この場合 のスイッチング順序は以下のようになる。

$$
\underset{(R T T)}{d_{\delta \alpha}} \rightarrow \underset{(R R T)}{d_{\delta \beta}} \rightarrow \underset{(R R S)}{d_{\gamma \beta}} \rightarrow \underset{(R S S)}{d_{\gamma \alpha}} \rightarrow \underset{(S S S)}{d_{0}} \quad\left(\theta_{i n}^{*}>\frac{\pi}{6}\right)
$$

〈2.3〉 入力電流指令ベクトルが偶数セクタ（Fig. 5(b)） にある場合のスイッチングスイッチングパターン入力 電流指令べクトルが奇数セクタにある場合と同様に偶数セ クタ 0 にある場合 Fig. 5(b) のスイッチング順序を求めると 以下のようになる。

出力電圧指令ベクトルが奇数セクタ I (Fig. 6(a) )にある 場合

$$
\begin{aligned}
& \underset{(R R R)}{d_{0}} \rightarrow \underset{(R R S)}{d_{\delta \alpha}} \rightarrow \underset{(S R S)}{d_{\delta \beta}} \rightarrow \underset{(S T S)}{d_{\gamma \beta}} \rightarrow \underset{(T T S)}{d_{\gamma \alpha}} \quad\left(\theta_{i n}^{*}<\frac{\pi}{6}\right) \\
& \text {................ (18) } \\
& \underset{(R R S)}{d_{\delta \alpha}} \rightarrow \underset{(S R S)}{d_{\delta \beta}} \rightarrow \underset{(S T S)}{d_{\gamma \beta}} \rightarrow \underset{(T T S)}{d_{\gamma \alpha}} \rightarrow \underset{(T T T)}{d_{0}} \quad\left(\theta_{i n}^{*}>\frac{\pi}{6}\right)
\end{aligned}
$$

出力電圧指令ベクトルが偶数セクタ 0 (Fig. 6(b)）にある 場合

$$
\begin{array}{r}
\underset{(R R R)}{d_{0}} \rightarrow \underset{(R R S)}{d_{\delta \beta}} \rightarrow \underset{(R S S)}{d_{\delta \alpha}} \rightarrow \underset{(T S S)}{d_{\gamma \alpha}} \rightarrow \underset{(T T S)}{d_{\gamma \beta}} \quad\left(\theta_{i n}^{*}<\frac{\pi}{6}\right) \\
\ldots \ldots \ldots \cdots \cdots \cdots \\
\underset{(R R S)}{d_{\delta \beta}} \rightarrow \underset{(R S S)}{d_{\delta \alpha}} \rightarrow \underset{(T S S)}{d_{\gamma \alpha}} \rightarrow \underset{(T T S)}{d_{\gamma \beta}} \rightarrow \underset{(T T T)}{d_{0}}
\end{array}\left(\begin{array}{l}
\left.\theta_{i n}^{*}>\frac{\pi}{6}\right) \\
(T T S)
\end{array}\right.
$$

以上，(14) (17) 式䇽よび (18) （21) 式よりキャリア周 期間でのスイッチング順序は以下のように場合分けできる。

入力電流指令ベクトルと出力電圧指令ベクトルのセク夕 の合計が偶数の場合

$$
\begin{aligned}
& d_{0} \rightarrow d_{\delta \beta} \rightarrow d_{\delta \alpha} \rightarrow d_{\gamma \alpha} \rightarrow d_{\gamma \beta} \quad\left(\theta_{i n}^{*}<\frac{\pi}{6}\right) \ldots \ldots \\
& d_{\delta \beta} \rightarrow d_{\delta \alpha} \rightarrow d_{\gamma \alpha} \rightarrow d_{\gamma \beta} \rightarrow d_{0} \quad\left(\theta_{i n}^{*}>\frac{\pi}{6}\right) \ldots \ldots
\end{aligned}
$$

入力電流指令ベクトルと出力電圧指令ベクトルのセクタ の合計が奇数の場合

$$
\begin{aligned}
& d_{0} \rightarrow d_{\delta \alpha} \rightarrow d_{\delta \beta} \rightarrow d_{\gamma \beta} \rightarrow d_{\gamma \alpha} \quad\left(\theta_{i n}^{*}<\frac{\pi}{6}\right) \ldots \\
& d_{\delta \alpha} \rightarrow d_{\delta \beta} \rightarrow d_{\gamma \beta} \rightarrow d_{\gamma \alpha} \rightarrow d_{0} \quad\left(\theta_{i n}^{*}>\frac{\pi}{6}\right) \ldots
\end{aligned}
$$

\section{3. パルスパターンを改善した空間ベクトル変調}

提案する空間ベクトル変調についても, Table 2 の各パ ターンのデューティを求める手順までは, 従来形空間べク トル変調のものと共通である。よって，それ以降の PWM パターン発生法について述べる。

まず，各パターンのデューティをマトリックスコンバー タの各スイッチのデューティへ変換する。例として, Fig. 3, Fig. 4 のように入力電流指令ベクトルがセクタ I, 出力電圧 指令ベクトルがセク夕 0 , かつ $\theta_{i n}^{*}$ が $\pi / 6$ より小さい場合 を考える。この区間に打ける出力パターンとそれに対応す るデューティの関係は Table 2 より Table 3 のようになる。 これをマトリックスコンバータの各スイッチの接続デュー ティ $d_{R U} \sim d_{T W}$ に変換する。

$\langle\mathbf{3 \cdot 1}\rangle$ 出力 $\boldsymbol{U}$ 相への接続デューティ Table 3 より 出力 $U$ 相に $R$ 相が接続される場合の接続デューティは $d_{\gamma \alpha}+d_{\gamma \beta}+d_{\delta \alpha}+d_{\delta \beta}$ であるから, $d_{R U}$ は以下のようになる。

$$
d_{R U}=d_{\gamma \alpha}+d_{\gamma \beta}+d_{\delta \alpha}+d_{\delta \beta}
$$

同様に出力 $U$ 相に $S$ 相が接続される場合の接続デュー ティは 0 より， $d_{S U}$ は以下のようになる。

$$
d_{S U}=0
$$

同様に $T$ 相との接続デューティは $d_{0}$ より,$d_{T U}$ は以下 のようになる。

$$
d_{T U}=d_{0}
$$

$\langle\mathbf{3} \cdot \mathbf{2}\rangle$ 出力 $V$ 相への接続デューティ 出力 $U$ 相と同 様に, Table 3 から出力 $V$ 相に各入力相が接続される場合 の接続デューティ $d_{R V} \sim d_{T V}$ を求めると以下のようになる。

$$
\begin{aligned}
& d_{R V}=d_{\gamma \beta}+d_{\delta \beta} \\
& d_{S V}=d_{\gamma \alpha} \cdots \\
& d_{T V}=d_{0}+d_{\delta \alpha} .
\end{aligned}
$$

$\langle\mathbf{3} \cdot \mathbf{3}\rangle$ 出力 $\boldsymbol{W}$ 相への接続デューティ 出力 $U, V$ 相 と同様に, Table 3 から出力 $W$ 相に各入力相が接続される 場合の接続デューティ $d_{R W} \sim d_{T W}$ を求めると以下のように なる。

$$
\begin{aligned}
& d_{R W}=0 \cdots \cdots \\
& d_{S W}=d_{\gamma \alpha}+d_{\gamma \beta} \ldots \\
& d_{T W}=d_{\delta \alpha}+d_{\delta \beta}+d_{0}
\end{aligned}
$$

Table 3. The relation between pattern and duty (Input current hexagon: I, Output voltage hezagon: $0, \theta_{i n}^{*}<\pi / 6$ )

\begin{tabular}{|c|c|c|c|c|c|}
\hline duty & $d_{\gamma \alpha}$ & $d_{\gamma_{\beta}}$ & $d_{\delta \alpha}$ & $d_{\delta \beta}$ & $d_{0}$ \\
\hline Pattern & $R S S$ & $R R S$ & $R T T$ & $R R T$ & $T T T$ \\
\hline
\end{tabular}




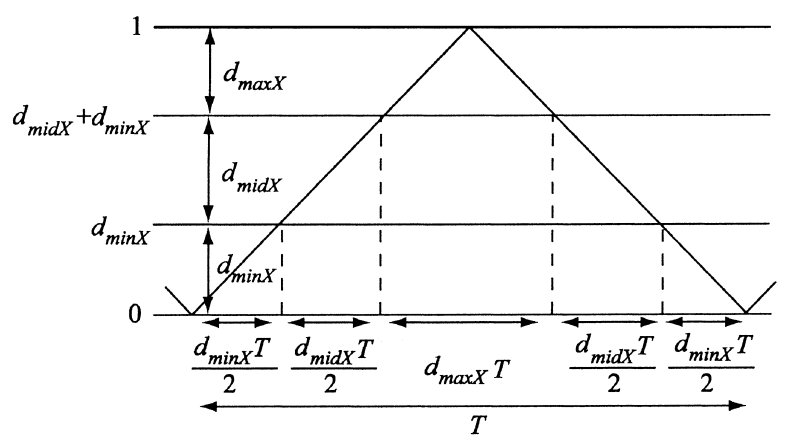

Fig. 7. Method of PWM pattern generation

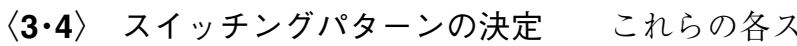
イッチのデューティを Fig. 7 に示すように出力相ごとにキャ リア比較することで最終的なスイッチングパターンを求め る (7)。ここで, $d_{\min X}, d_{\operatorname{midX}}, d_{\max X}$ は, それぞれ出力 $X$ 相 $(X=U, V, W)$ と入力最小相, 入力中間相, 入力最大相 との接続デューティである。今の例では, 出力 $U$ 相に対し ては $d_{\min X}, d_{\operatorname{midX}}, d_{\max X}$ はそれぞれ $d_{S U}, d_{T U}, d_{R U}$ とな る。Fig. 7 のような比較が, 出力 $U$ 相, $V$ 相, $W$ 相に対し てそれぞれ行われる。このキャリア比較法を用いることに よって，各出力相は 1 キャリア周期において入力最小相 $\rightarrow$ 入力中間相 $\rightarrow$ 入力最大相 $\rightarrow$ 入力中間相 $\rightarrow$ 入力最小相の順序 で接続される。したがって, 各出力相が入力最小相 $\rightarrow$ 入力

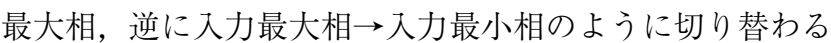
パターンがなくなるため, 従来の空間ベクトル変調に比べ 出力電圧の高調波が減少する。

\section{4. シミュレーション結果}

シミュレーションプログラムPSIM を用いて, Table 4 に 示す条件で，従来の空間べクトル変調および提案の空間べ クトル変調のシミュレーションを行った。従来の空間べク トル変調および提案の空間べクトル変調のシミュレーショ ン結果をそれぞれ Fig. 8, Fig.9 に示す。波形は，上から電 源 $R$ 相電圧 $e_{R}$, 電源 $R$ 相電流 $i_{R}$, 出力線間電圧 $e_{u v}$, 出力電 流 $i_{u}$ である。また，電源 $R$ 相電流 $i_{R}$ の拡大波形を Fig. 10, Fig. 11 に, 出力線間電圧 $e_{u v}$ の拡大波形を Fig. 12, Fig. 13 に示す。さらに，Fig. 14，Fig. 15 にそれぞれ従来の空間べ クトル変調，提案の空間ベクトル変調を用いた場合の入力 電流 $i_{R}$ の高調波解析結果を示す。これらの結果から，従来 の空間ベクトル変調では出力電圧指令に関わらず入力最大 の線間電圧を用いて PWM 変調が行われているのに対し， 提案の空間ベクトル変調では，出力電圧指令が $173 \mathrm{~V}$ の変 調率が高い場合に，入力最大の線間電圧を用いて PWM 変 調が行われ，出力電圧指令が $50 \mathrm{~V}$ の変調率が低い場合に は，入力最大の線間電圧を用いずに PWM 変調が行われて いることがわかる。

Fig. 16 に出力線間電圧実効値に対する THD 特性を示す。 同図より，提案の空間ベクトル変調では入力最大相一最小相 間のスイッチングを無くしたことで，従来の空間ベクトル
Table 4. Specification for simulation

\begin{tabular}{|c|l|}
\hline Input voltage & $200 \mathrm{~V} / 60 \mathrm{~Hz}$ \\
\hline Output voltage referece & $173 \mathrm{~V} / 30 \mathrm{~Hz}, 50 \mathrm{~V} / 30 \mathrm{~Hz}$ \\
\hline Input filter & $L=0.15 \mathrm{mH}, C=25 \mu \mathrm{F}$ \\
\hline Carrier frequency & $10 \mathrm{kHz}$ \\
\hline Load & $5 \Omega, 20 \mathrm{mH}$ \\
\hline
\end{tabular}

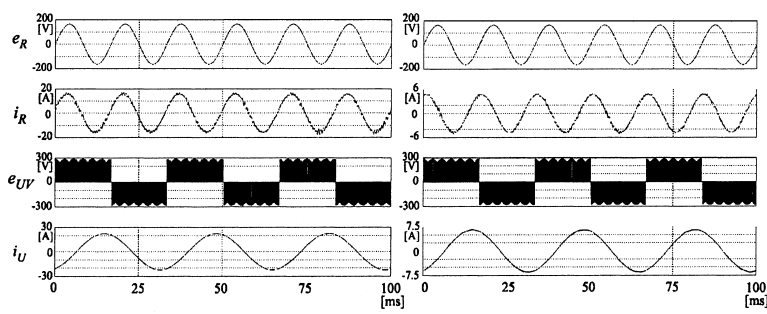

$\begin{array}{lll}\text { (a) Output voltage reference } 173 \mathrm{~V} & \text { (b) Output voltage reference } 50 \mathrm{~V}\end{array}$

Fig. 8. Various waveforms for conventional SVM
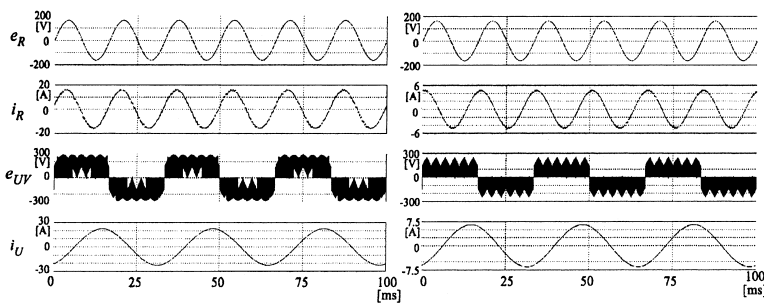

(a) Output voltage reference $173 \mathrm{~V}$

(b) Output voltage reference $50 \mathrm{~V}$

Fig. 9. Various waveforms for proposed SVM

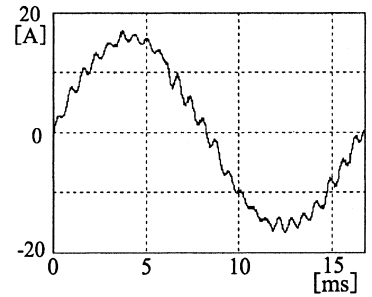

(a) Output voltage reference $173 \mathrm{~V}$

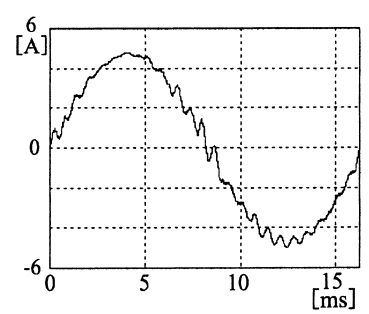

(b) Output voltage reference $50 \mathrm{~V}$
Fig. 10. Input current waveforms (conventional SVM)

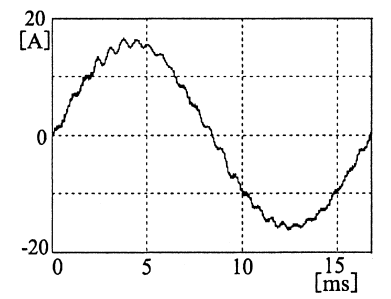

(a) Output voltage reference $173 \mathrm{~V}$

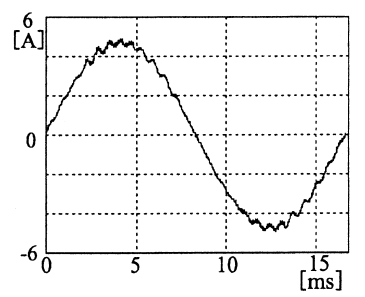

(b) Output voltage reference $50 \mathrm{~V}$

Fig. 11. Input current waveforms (proposed SVM)

変調より高調波を低減できていることがわかる。

Fig. 17, Fig. 18 にはそれぞれ従来の空間ベクトル変調お よび提案の空間ベクトル変調を用いた場合の出力線間電圧 $e_{u v}$ の高調波解析結果を示す。これらの図より, 提案の空間 ベクトル変調では, キャリア周波数の整数倍付近において 鋭いピークが出ているものの，それ以外の成分に関しては 低減できていることがわかる。これは，提案法では，Fig.7 

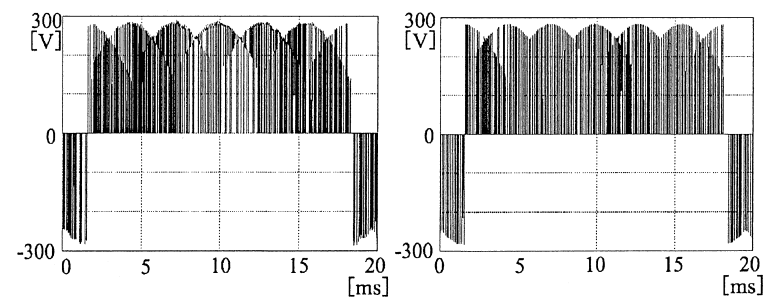

(a) Output voltage reference $173 \mathrm{~V}$

(b) Output voltage reference $50 \mathrm{~V}$

Fig. 12. Output line to line voltage waveforms (conventional SVM)

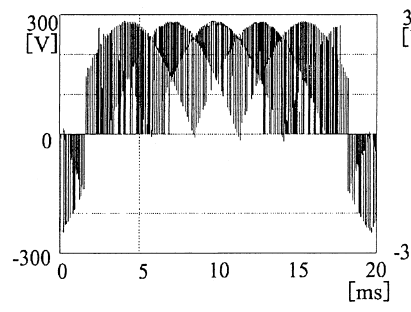

(a) Output voltage reference $173 \mathrm{~V}$

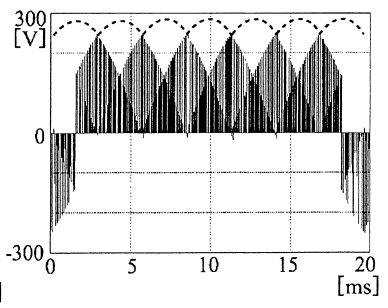

(b) Output voltage reference $50 \mathrm{~V}$
Fig. 13. Output line to line voltage waveforms (proposed SVM)

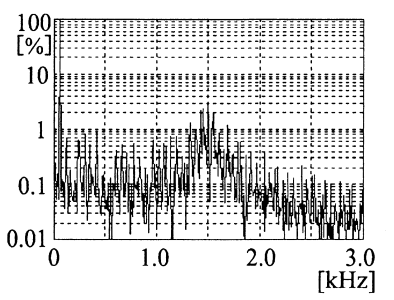

(a) Output voltage reference $173 \mathrm{~V}$

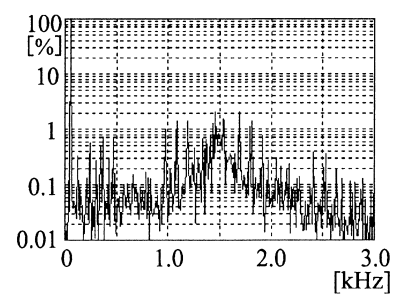

(b) Output voltage reference $50 \mathrm{~V}$
Fig. 14. Frequency spectra of input current (conventional SVM)

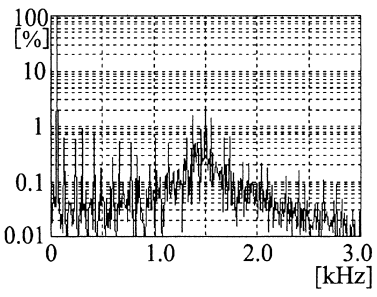

(a) Output voltage reference $173 \mathrm{~V}$

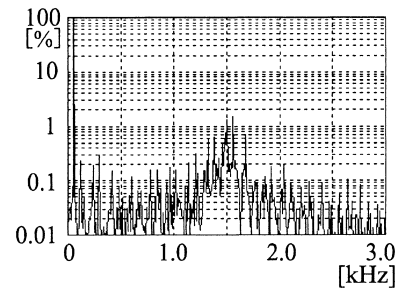

(b) Output voltage reference $50 \mathrm{~V}$
Fig. 15. Frequency spectra of input current (proposed SVM)

のキャリア比較により各出力相電圧がキャリア周期の中心 でピーク值をとるため，キャリア周波数の整数倍付近の高 調波成分において鋭いピークが出ているのに対し，従来法 では入力最大相一最小相間のスイッチングにより，キャリア 周波数の整数倍付近以外の高調波成分 $(1 \mathrm{kHz}$ 以下の低次 高調波を含む) が大きくなっているためと考えられる。

Fig. 19，Fig. 20 にそれぞれ従来の空間ベクトル変調およ び提案の空間ベクトル変調を用いた場合の出力電流高調波 解析結果を示す。同図より，提案の空間べクトル変調を用 いれば出力電流の低次高調波成分を低減でき，電動機を負 荷にした場合，トルクリプルが抑制できると考えられる。

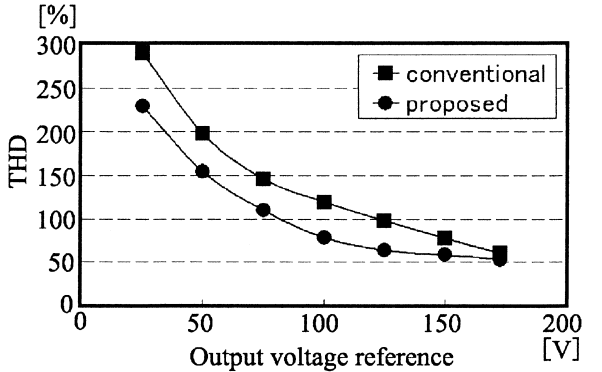

Fig. 16. THD of output line to line voltage

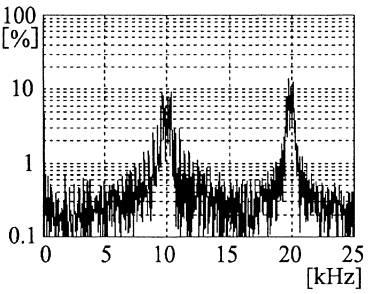

(a) Output voltage reference $173 \mathrm{~V}$

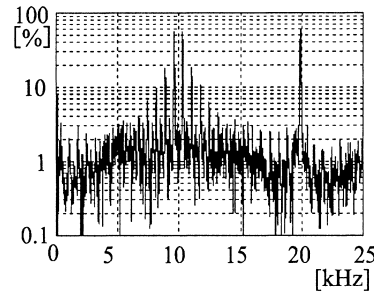

(b) Output voltage reference $50 \mathrm{~V}$
Fig. 17. Frequency spectra of output line to line voltage (conventional SVM)

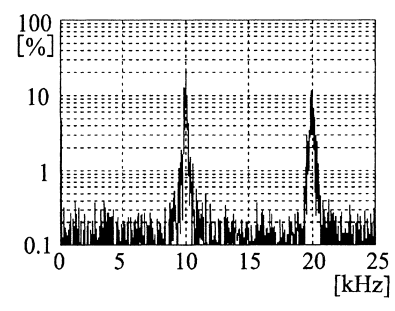

(a) Output voltage reference $173 \mathrm{~V}$

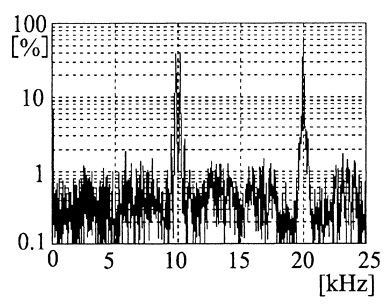

(b) Output voltage reference $50 \mathrm{~V}$
Fig. 18. Frequency spectra of output line to line voltage (proposed SVM)

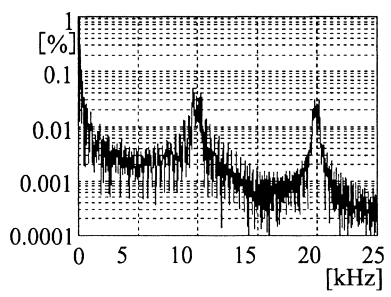

(a) Output voltage reference $173 \mathrm{~V}$

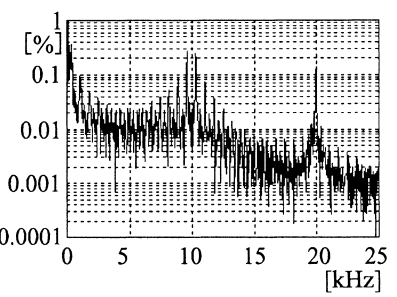

(b) Output voltage reference $50 \mathrm{~V}$
Fig. 19. Frequency spectra of output current (conventional SVM)

Fig. 21, Fig. 22 にそれぞれ従来の空間ベクトル変調およ び提案の空間べクトル変調を用いた場合の電源中性点に対 する出力相電圧 $e_{U}, e_{V}, e_{W}$ のキャリア周期間の波形を示 す。Fig. 21, Fig. 22 より, 従来の空間ベクトル変調を用い た場合，各出力相が入力の最小相から最大相へ，あるいは 入力の最大相から最小相へ切り替えられるパターンが存在 するのに対し，提案の空間べクトル変調ではそのようなパ ターンが存在しないことがシミュレーション結果からも確 認できる。さらに出力電圧指令が $50 \mathrm{~V}$ の場合において，提 案の空間ベクトル変調は, 従来の空間ベクトル変調に比べ てキャリア周期間の零ベクトルの割合が大きく減少してい 


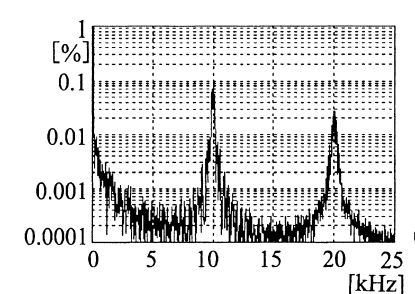

(a) Output voltage reference $173 \mathrm{~V}$

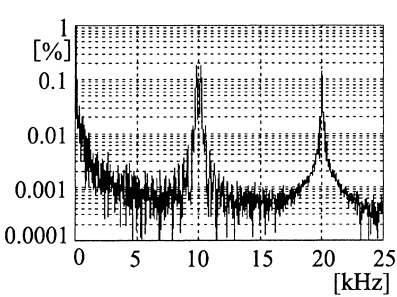

(b) Output voltage reference $50 \mathrm{~V}$
Fig. 20. Frequency spectra of output current (proposed SVM)

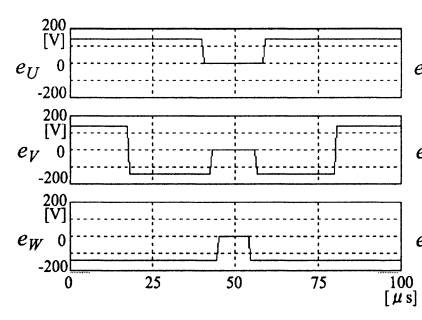

(a) Output voltage reference $173 \mathrm{~V}$

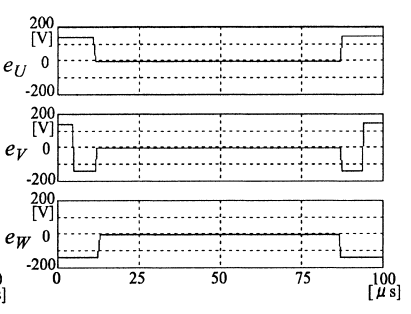

(b) Output voltage reference $50 \mathrm{~V}$
Fig. 21. Output phase voltage waveforms (conventional SVM)

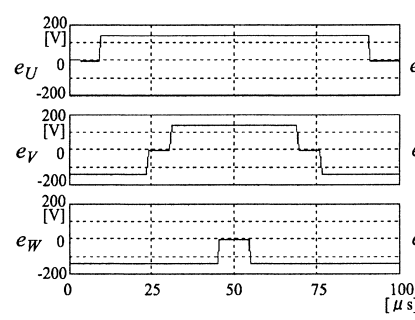

(a) Output voltage reference $173 \mathrm{~V}$

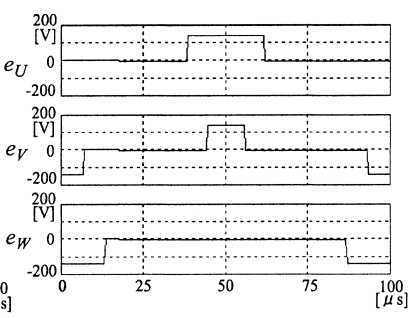

(b) Output voltage reference $50 \mathrm{~V}$
Fig. 22. Output phase voltage waveforms (proposed SVM)

ることがわかるこれは, 従来の空間ベクトル変調で出力電 圧指令が低くなる際，零ベクトルのデューティ $d_{0}$ が増大す るのみで出力パターンが変化しないのに対し, 提案の空間べ クトル変調では各出力相が入力中間相に接続されるデュー ティが増大することによって，出力の線間に入力最大の線 間電圧を発生させるパターンがなくなるためである。この ことは，従来の空間べクトル変調，提案の空間ベクトル変 調を用いた場合に対して計算した Fig. 12, Fig. 13 の出力線 間電圧波形からも確認できる。このように，提案法を用い れば出力電圧指令が低いとき，より低い電圧を用いて非零 ベクトルの出力時間を長くすることができるため実システ ムにおいて，転流時間の影響を従来法より小さくできると 考えられる。

\section{5. まとめ}

本論文では，マトリックスコンバータの従来の空間ベク トル変調法より求められた出力パターンのデューティをマ トリックスコンバータの各スイッチのデューティへと変換 し，それを出力相ごとにキャリア比較することによって最 終的なスイッチングパターンを決定する方式を提案した。
この変調方式を用いれば，各出力相電圧が入力最小相電圧 から入力最大相電圧へ, 逆に入力最大相電圧から入力最小 相電圧へ直接切り替わるスイッチングパターンがなくなる ため，マトリックスコンバータの出力電圧の高調波を低減 できる。また，出力電流の低次高調波成分も抑制すること ができるため，電動機を負荷とした場合においてトルクリ プルの低減も可能であると考えられる。

(平成 19 年 3 月 8 日受付, 平成 19 年 6 月 21 日再受付)

\section{文献}

(1) H. Hara, E. Yamamoto, M. Zenke, J.-K. Kang, and T. Kume: "An Improvement of Output Voltage Control Performance for Low Voltage Region of Matrix Converter", Proc. 2004 Japan Industry Applications Society Conference, No.1-48, (2004) (in Japanese)

原 英則・ 山本英治·善家充彦·姜 俊求·久米常生 :「低電圧領域 に扔けるマトリクスコンバータの電圧改善の一方策」, 平 16 年電学 産業応用部門大会, No.1-45 (2004)

(2) J. Ito, I. Sato, H. Ohgushi, K. Sato, A. Odaka, and N. Eguchi: "A Control Method for Matrix Converter Based on Virtual AC/DC/AC Conversion Using Carrier Comparison Method", T. IEE Japan IA, Vol.124-D, No.5, pp.457-463 (2004-5) (in Japanese)

伊東淳一 ·佐藤以久也 - 大口英樹 - 佐藤和久 - 小高章弘 - 江口直也 : 「キャリア比較方式を用いた仮想 $\mathrm{AC} / \mathrm{DC} / \mathrm{AC}$ 変換方式によるマトリッ クスコンバータの制御」, 電学論 D, 124, 5, pp.457-463 (2004-5)

(3) H.J. Cha and P. Enjeti: "An Approach to Reduce Common Mode Voltage in Matrix Converter", IEEE Trans. Ind. Applicat., Vol.39, pp.1151-1159 (2003)

(4) L. Helle, K.B. Larsen, A.H. Jorgensen, S.M. Nielsen, and F. Blaabjerg: "Evaluation of Modulation Schemes for Three-Phase Matrix Converters", IEEE Trans. Ind. Electron., Vol.51, pp.158-171 (2004)

(5) L. Huber and D. Borojevic: "Space vector modulated three-phase to three phase matrix converter with input power factor correction", IEEE Trans. Ind. Applicant., Vol.31, pp.1234-1246 (1995)

(6) A. Odaka, I. Sato, H. Ohgushi, Y. Tamai, H. Mine, and J. Ito: "A PAM Control Method for Matrix Converter", Proc. 2005 Japan Industry Applications Society Conference, No.1-43 (2005) (in Japanese) 小高章弘·佐藤以久也·大口英樹 - 玉井康寛·美根宏則 ·伊東淳一: 「仮 想 AC/DC/AC 変換方式に基づいたマトリックスコンバータの PAM 制御法」, 平 17 電学産業応用部大, No.1-43 (2005)

(7) H. Shimada and T. Takeshita: "PWM Cpntrol of Therr-Phase to Three-Phase Matrix Converter for Reducing Output Voltage Harmonics", The Papers of Joint Technical Meeting on Semiconductor Power Converter and Industry Electric and Electric Application, IEE Japan, SPC-05-48/IEA-05-4, pp.1318 (2005) (in Japanese)

島田大志・竹下隆晴 : 「出力電圧高調波の低減に着目した三相/三相 マトリックスコンバータの PWM 制御,, 電学半導体電力変換, 産業 電力電気応用合同研資, SPC-05-48/IEA-05-4, pp.13-18 (2005)

(8) K. Yamamoto, K. Shinohara, and T. Mori: "Improvement of Pulse Pattern for Space Vector Modulated Matrix Converter", The Papers of Joint Technical Meeting on Semiconductor Power Converter and Industry Electric and Electric Application, IEE Japan, SPC-05-48/IEA-05-4, pp.13-18 (2006) (in Japanese)

山本吉朗・篠原勝次・森 辰也 :「マトリックスコンバー夕の空間 ベクトル変調におけるパルスパターンの改善」, 電学半導体電力変換, 産業電力電気応用合同研資, SPC-06-159/IEA-06-54, pp.77-82 (2006)

山 本 吉 朗 (正員) 1965 年 1 月 11 日生。1989 年 3 月鹿児島

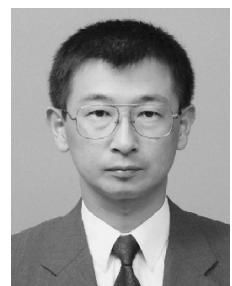
大学大学院工学研究科電気工学専攻修士課程修了。 同年 4 月鹿児島工業高等専門学校助手, 1993 年 4 月鹿児島大学工学部電気電子工学科助手, 2007 年 4 月同助教授, 現在に至る。工学博士, 主として, 電動機のインバー夕駆動に関する研究に従事。 
篠 原 勝 次 (正員) 1943 年 1 月 2 日生。1968 年 3 月九州工

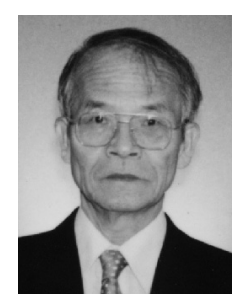
業大学大学院制御工学専攻修士課程修了。(株) 安 川電機製作所を経て, 1977 年 3 月九州工業大学 助手, 1985 年 4 月鹿児島大学工学部助教授, 1992 年 4 月同教授，現在に至る。工学博士，主として， 電動機のインバー夕駆動に関する研究に従事。
森 辰

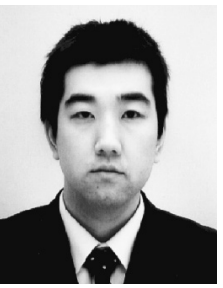

（学生員） 1981 年 9 月 3 日生。 2006 年 3 月鹿児 島大学工学部電気電子工学科卒業。同年 4 月鹿児 島大学大学院理工学研究科電気電子工専攻博士前 期課程入学, 現在に至る。主として, マトリック スコンバータ制御の研究に従事。 